\title{
Poly[3-methyl-1,3-oxazolidin-2-iminium $\left[\mu_{3}\right.$-cyanido-tri- $\mu_{2}-$ cyanido- $\kappa^{9} \mathrm{C}: \mathrm{N}$-tricuprate(I)]]
}

\author{
Leena N. Rachid and Peter W. R. Corfield *(i)
}

\author{
Chemistry Department, Fordham University, 441 East Fordham Road, Bronx, New York, NY 10458, USA; \\ lrachid@fordham.edu \\ * Correspondence: pcorfield@fordham.edu; Tel.: +1-718-817-4454
}

check for

updates

Citation: Rachid, L.N.; Corfield, P.W.R. Poly[3-methyl-1,3-oxazolidin2-iminium $\left[\mu_{3}\right.$-cyanido-tri- $\mu_{2}$ cyanido- $\kappa^{9} \mathrm{C}: \mathrm{N}$-tricuprate $\left.\left.(\mathrm{I})\right]\right]$. Molbank 2021, 2021, M1259. https:/ / doi.org/10.3390/M1259

Academic Editors: Stefano D'Errico and Annalisa Guaragna

Received: 15 June 2021

Accepted: 16 July 2021

Published: 26 July 2021

Publisher's Note: MDPI stays neutral with regard to jurisdictional claims in published maps and institutional affiliations.

Copyright: (c) 2021 by the authors. Licensee MDPI, Basel, Switzerland. This article is an open access article distributed under the terms and conditions of the Creative Commons Attribution (CC BY) license (https:/ / creativecommons.org/licenses/by/ $4.0 /)$.

\begin{abstract}
The unexpected formation of an oxazole ring has occurred during synthesis of a copper(I) cyanide network polymer as part of our ongoing studies of the structural chemistry of these networks. Crystals of the title compound were formed during the synthesis of a previously reported $\mathrm{CuCN}$ network solid containing protonated $N$-methylethanolamine and have been characterized by single crystal X-ray structure analysis. The structure shows well-defined oxazole-2-iminium cations sitting in continuous channels along the short a-axis of the crystal in a new three-dimensional copper(I) cyanide polymeric network. Evidently, a reaction has occurred between the cyanide ion and the protonated $\mathrm{N}$-methylethanolamine base.
\end{abstract}

Keywords: oxazole; iminium; unexpected product; copper cyanide; network; cuprophilic

\section{Introduction}

We report here the unexpected formation of poly[3-methyl-1,3-oxazolidin-2-iminium $\left[\mu_{3}\right.$-cyanido-tri- $\mu_{2}$-cyanido- $\kappa^{9} \mathrm{C}: \mathrm{N}$-tricuprate $\left.\left.(\mathrm{I})\right]\right],(\mathbf{1}$, Scheme 1$)$ during preparative studies of $\mathrm{NaCN} / \mathrm{CuCN} / \mathrm{N}$-methylethanolamine (meoen) mixtures as part of our ongoing studies of the structural chemistry of copper(I) cyanide networks. The usual product was [meoenH] $\left[\mathrm{Cu}_{2}(\mathrm{CN})_{3}\right], 2$, (Scheme 1) obtained as tetragonal crystals after one or two weeks, with a structure that contains meoenH cations embedded in an anionic three-dimensional $\mathrm{CuCN}$ network [1]. In efforts to obtain more product, we allowed further fractions to crystallize from the filtrates. The title compound was obtained from such fractions as crystals with a platelike morphology rather than the rods usually obtained for the expected compound 2. The crystal structure analysis reported here shows that a reaction between the cyanide ion and the ethanolamine cation has occurred (Scheme 2) to cause ring closure and the formation of an $N$-methylated 1,3-oxazole ring with a 2-iminium group, which acts as cation guest in a 3D anionic copper(I) cyanide network. Oxazole chemistry is a mature field [2-5] and oxazoles play an important role in pharmaceutical chemistry [6]. Oxazole synthesis has been achieved in at least fifteen different types of reactions [4], but we are not aware of a reaction similar to that reported here. There is less literature on the 2-iminium derivatives, and a search of the Cambridge Structural Database (CSD) [7] indicated only three crystallographic studies of their 2-iminium salts [8-10]. Reference 8 gives the structure of an oxaolidin-2-iminium ring with a seven-membered ring fused at C4 and C5, whereas the other references refer to the simple ring with various substituents. 


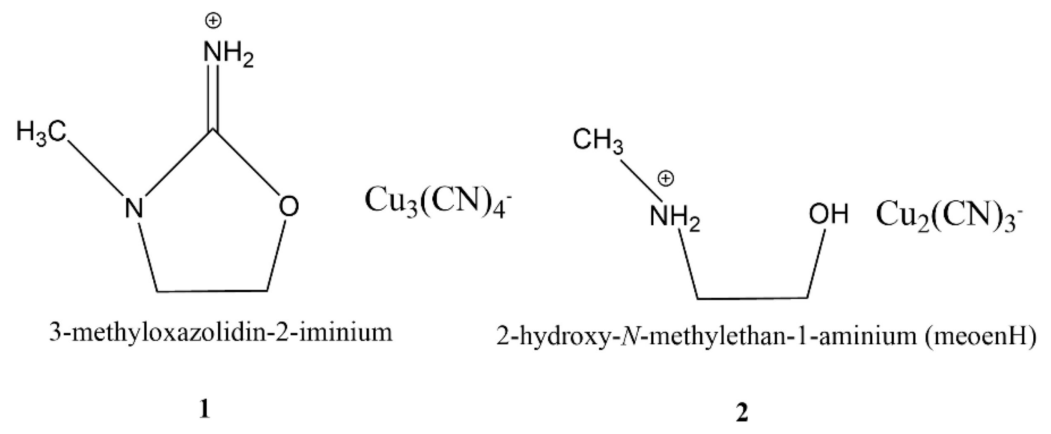

Scheme 1. Structures of the title compound, $\mathbf{1}$, and of the expected product, $\mathbf{2}$.

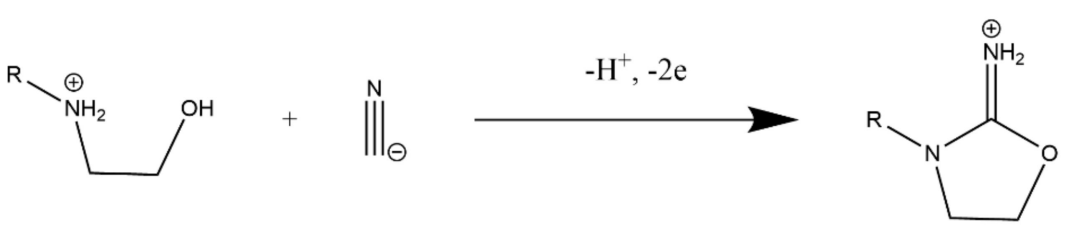

Scheme 2. Reaction of protonated N-methylethanolamine with cyanide ion.

\section{Results}

\subsection{Synthesis}

The title compound, $\mathbf{1}$, is almost always obtained from the second or third crystal fraction from aqueous mixtures of the neutralized $\mathrm{N}$-methylethanolamine and $\mathrm{CuCN} / \mathrm{NaCN}$ solutions after two or more weeks. Inevitably the first fraction obtained contains crystals of 2 , sometimes mixed with a green powder. Although we have varied concentrations and the $\mathrm{pH}$, we have not yet developed a procedure that will reliably give $\mathbf{1}$ as the first fraction. A typical synthesis involved mixing $0.90 \mathrm{~g}(10 \mathrm{mmol})$ of $\mathrm{CuCN}$ with $0.78 \mathrm{~g}(16 \mathrm{mmol})$ of $\mathrm{NaCN}$ in $60 \mathrm{~mL}$ of water until dissolved and adding a solution with volume $95 \mathrm{~mL}$ containing $3.00 \mathrm{~g}(40 \mathrm{mmol})$ meoen base neutralized with $\mathrm{HCl}(\mathrm{aq})$ to a $\mathrm{pH}$ of 2 . The first precipitated fraction was filtered off after two weeks, and a second fraction filtered three weeks later gave $0.17 \mathrm{~g}$ of $\mathbf{1}$ as colorless plates, from which the crystal used for the X-ray analysis was selected. When air was excluded, no solid precipitated, suggesting that dioxygen from the air was the oxidant.

Sometimes pale or dark green crystals of $\mathbf{1}$ were obtained, shown by $\mathrm{X}$-ray analysis to have the same structure as reported here. The dark green "crystals" shown in Figure 1 were very irregular in shape, yet diffracted well, and showed no extra diffraction pattern due to a separate phase. Examination optically at higher magnification (Figure S2) and with a scanning electron microscope (Figure S3) confirmed the presence of what looks like an amorphous phase deposited on crystalline material. Some of the sample was ground and examined by electron spin resonance-separate green and white particles were now visible. The esr spectrum, recorded as a first derivative absorption curve, (Figure S4) clearly shows the presence of $\mathrm{Cu}(\mathrm{II})$. $\mathrm{Cu}(\mathrm{II})-\mathrm{N}$ bonding is indicated by the sharp secondary hyperfine lines that correspond the interaction of ${ }^{14} \mathrm{~N}$ with the unpaired electron associated with the $\mathrm{Cu}$ (II) ion. We conclude that the "green" crystals are composed of colorless crystalline plates of 1 capped with deposits of a green amorphous phase that contains $\mathrm{Cu}(\mathrm{II})$, probably in the form of a mixed-valence copper cyanide complex. A similar phenomenon was reported in the analysis of the meoenH complex, 2 [1]. 


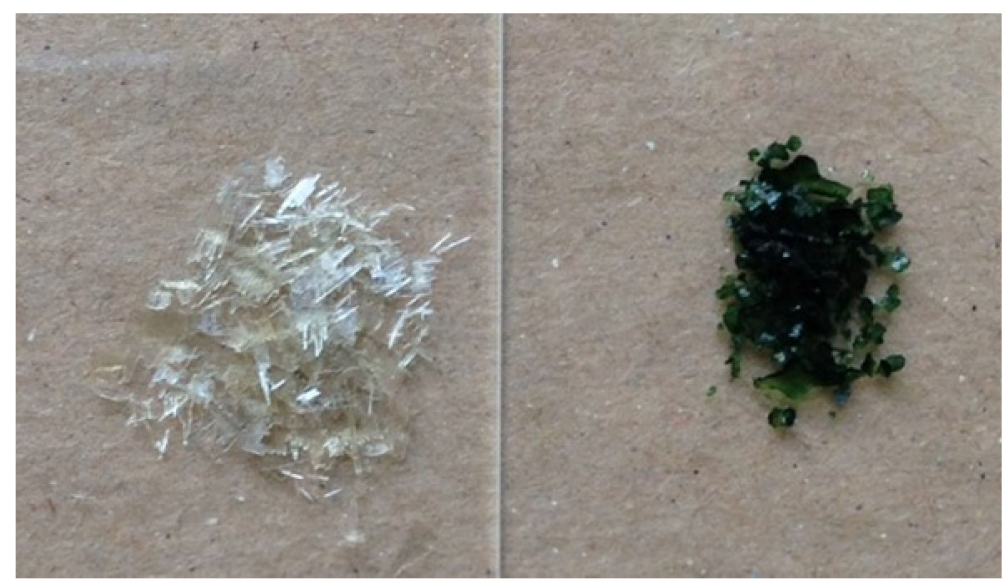

(a)

(b)

Figure 1. Photograph of crystalline samples of 1. (a) Colorless plates; (b) plates coated with green amorphous material, as text describes.

\subsection{X-Ray Structure}

The crystal structure is built up from the oxazolidin-2-iminium cations in channels in a three-dimensional $\mathrm{Cu}(\mathrm{I}) \mathrm{CN}$ network with overall stoichiometry $[\mathrm{LH}]\left[\mathrm{Cu}_{3}(\mathrm{CN})_{4}\right]$, where LH represents the cation. Figure 2a presents the crystallographic asymmetric unit, showing the thermal ellipsoids and atom numbering. Figure $2 b$ shows geometrical parameters for the oxazolidin-2-iminium cation. Atom numbering follows the typical convention for these rings; in the crystal structure, they are $\mathrm{O} 11, \mathrm{C} 12, \mathrm{~N} 13, \mathrm{C} 14$, etc., to avoid confusion with the cyanide atom numbers. The bond distances around C2 are essentially equal at $1.30 \AA$, indicating resonance between three hybrid structures with the positive charge spread over O1, N3, and N7. The four atoms O1, C2, N3, N7 are strictly coplanar, but the constraints of the five-membered ring and its asymmetry force significant deviations from the idealized $120^{\circ}$ angles: the internal angle is reduced to $114.1(3)^{\circ}$, while the external angle N7-C2-N3 at $127.2(4)^{\circ}$ is much larger than the angle $\mathrm{N} 7-\mathrm{C} 2-\mathrm{O} 1$, at $118.8(4)^{\circ}$. A similar geometry for this portion of the cation is seen in the three $\mathrm{X}$-ray structures of similar iminium cations mentioned earlier [8-10], even in reference [8], where there is no substituent on N3. Other bond lengths and angles seem normal.

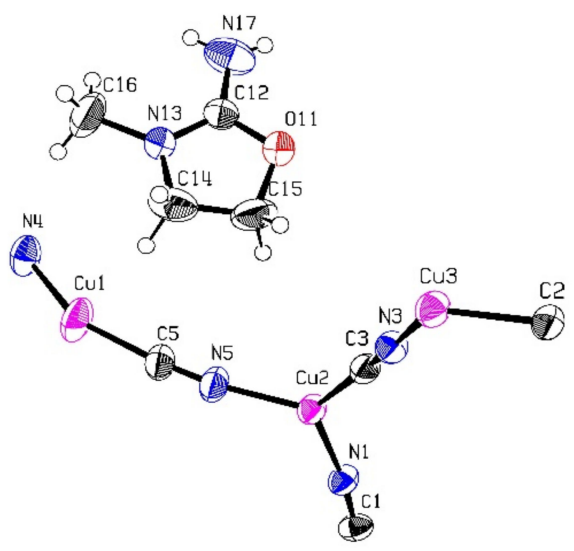

(a)

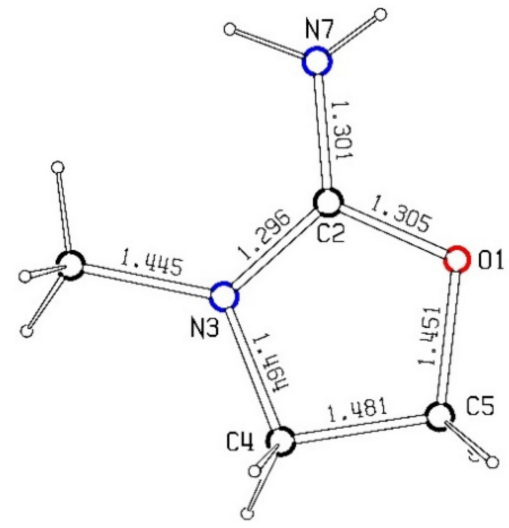

(b)

Figure 2. (a) Asymmetric unit for 1, showing thermal ellipsoids with $50 \%$ probability. Only one orientation of the disordered $\mathrm{CN}$ groups is shown. The $\mathrm{CN}$ groups $\mathrm{C} 2 \equiv \mathrm{N} 2$ and $\mathrm{C} 4 \equiv \mathrm{N} 4$ are each disordered about one of the inversion centers in the unit cell. (b) Bond lengths in the oxazolidin-2-iminium cation. Estimated standard deviations range from $0.004-0.007 \AA$. 
Each of the three $\mathrm{Cu}$ atoms in the $\mathrm{CuCN}$ network is involved in a cuprophilic interaction, with $\mathrm{Cu} 1$ close to $\mathrm{Cu} 2(\mathrm{x}-1, \mathrm{y}, \mathrm{z})$, and $\mathrm{Cu} 3$ close to $\mathrm{Cu} 3(2-\mathrm{x},-\mathrm{y}, 1-\mathrm{z})$. Such weak $\mathrm{d}^{10}-\mathrm{d}^{10}$ interactions are well known in $\mathrm{Cu}^{\mathrm{I}}$ complexes, and have been explored in a recent review [11]. They are common in our $\mathrm{CuCN}$ network studies. Each $\mathrm{Cu}$ atom has a different geometry, as seen in Figure 3. Cu1 has a distorted digonal geometry, with average $\mathrm{Cu}-\mathrm{CN}$ distance of 1.864(3) $\AA$ and angle at the $\mathrm{Cu}$ atom of $154.5(2)^{\circ}$ and is 2.632(1) $\AA$ from $\mathrm{Cu} 2(\mathrm{x}-1, \mathrm{y}, \mathrm{z})$. This cuprophilic interaction is without the bridging group(s) usually found in such structures, that help bring the $\mathrm{Cu}$ atoms close together-in the case of the $\mathrm{CuCN}$ structures, a $\mu_{3} \mathrm{CN}$ bridge. The present structure is unusual in this regard, as the cyanide group $\mathrm{C} 3 \equiv \mathrm{N} 3$ clearly seems to act as a $\mu_{2}$ bridging ligand, not as a $\mu_{3}$ bridge. It could possibly be regarded as forming a very asymmetric $\mu_{3}$ bridge, with $\mathrm{C} 3-\mathrm{Cu} 1(1+\mathrm{x}, \mathrm{y}, \mathrm{z})$ and C3-Cu2 distances of 2.631(3) $\AA$ and 1.929(3) $\AA$, but $2.631 \AA$ is longer than any $\mathrm{Cu}-\mathrm{CN}$ distances seen in a series of $63 \mu_{3} \mathrm{CN}-\mathrm{Cu}_{2}$ bridging bonds found in the Cambridge Structural Database [7], and the extreme asymmetry would lead one to expect a much greater $\mathrm{Cu}$ ... Cu distance than that found in the present structure [12]. Apart from its cuprophilic interaction with $\mathrm{Cu} 1$, atom $\mathrm{Cu} 2$ is trigonally coordinated with average $\mathrm{Cu}-\mathrm{CN}$ distance of $1.934(3) \AA$ and angles varying from $116.1(1)^{\circ}$ to $125.6(1)^{\circ}$. Cu3 is in a rough tetrahedral coordination to cyanide groups, with also a close interaction with $\mathrm{Cu} 3(2-\mathrm{x},-\mathrm{y}, 1-\mathrm{z})$, related by an inversion center. The Cu3 atoms are 2.730(1) $\AA$ apart and are bridged asymmetrically by a pair of symmetry related $\mu_{3} \mathrm{C} 1 \equiv \mathrm{N} 1$ groups, with $\mathrm{Cu}-\mathrm{CN}$ distances of 2.013(3) $\AA$ and 2.397(3) $\AA$. The remaining two Cu-CN distances are shorter, with Cu3-N2 =1.938(3) $\AA$ and $\mathrm{Cu} 3-\mathrm{N} 3=1.964(3) \AA$.

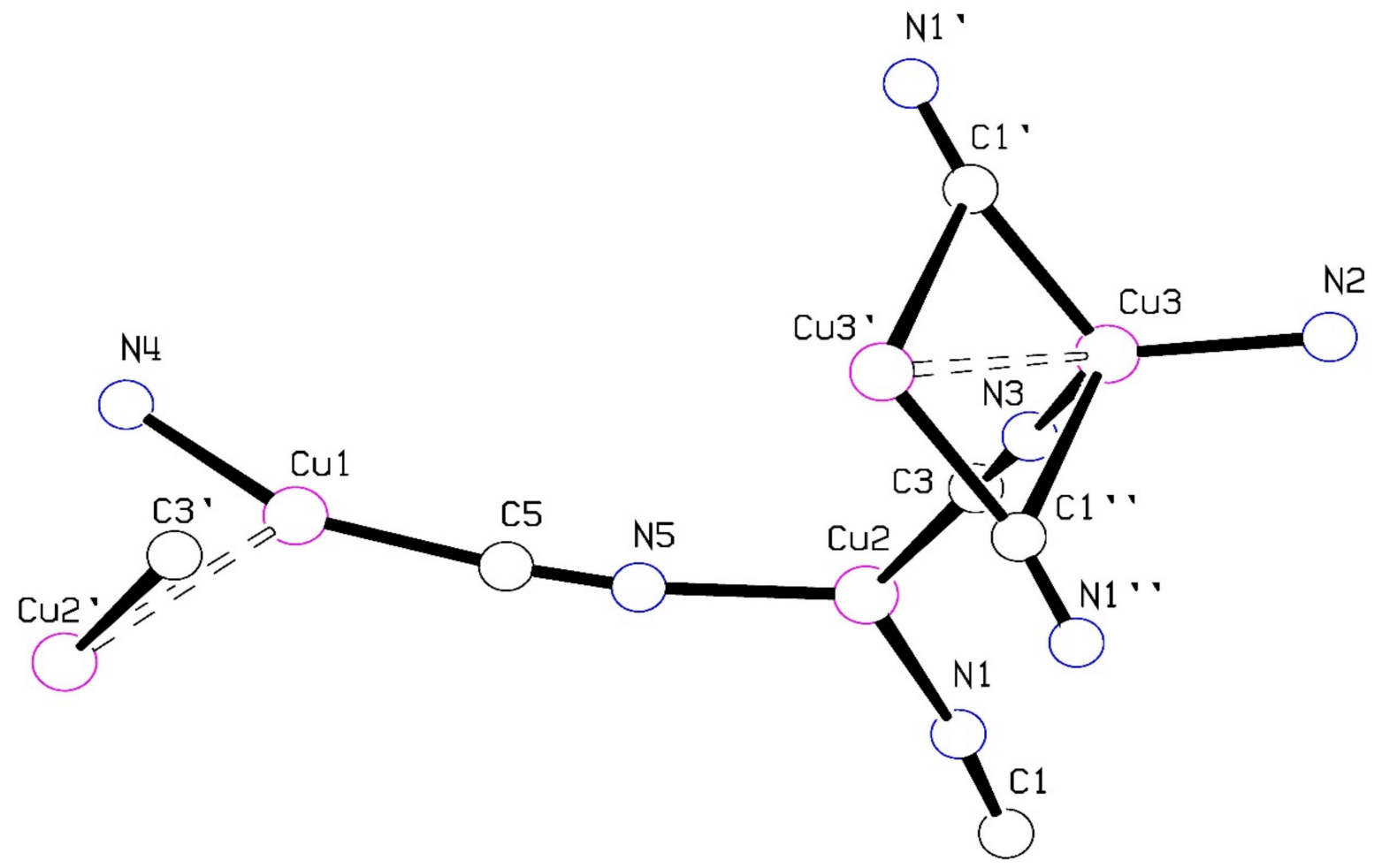

Figure 3. Coordination of the three copper atoms. Primed atoms are related by symmetry. Cuprophilic interactions are shown as dashed bonds.

The CuCN 3D network can be considered as made up of roughly planar networks connected by approximately vertical $\mathrm{Cu}-\mathrm{CN}-\mathrm{Cu}$ linkages which form walls to channels along the a-axis direction that contain the oxazalone-iminium cations, Figure 4 . The planar networks are made up of 24-membered rings composed of repeated-Cu2-C3N3-Cu3-C1N1$\mathrm{Cu} 2-$ linkages with the $\mathrm{Cu} 3$ cuprophilic pairs acting as nodes where four rings meet. A 
$\mathrm{Cu} 1-\mathrm{C} 4 \equiv \mathrm{N} 4-\mathrm{Cu} 1$ group forms a belt across the center of each 24-membered ring via the cuprophilic $\mathrm{Cu} 1$... Cu2 interactions. As seen in Figure 4a, the cations pack neatly into channels in the $\mathrm{CuCN}$ network. There are no obvious $\mathrm{H}$-bonding interactions between the cations and the anionic $\mathrm{CuCN}$ network.

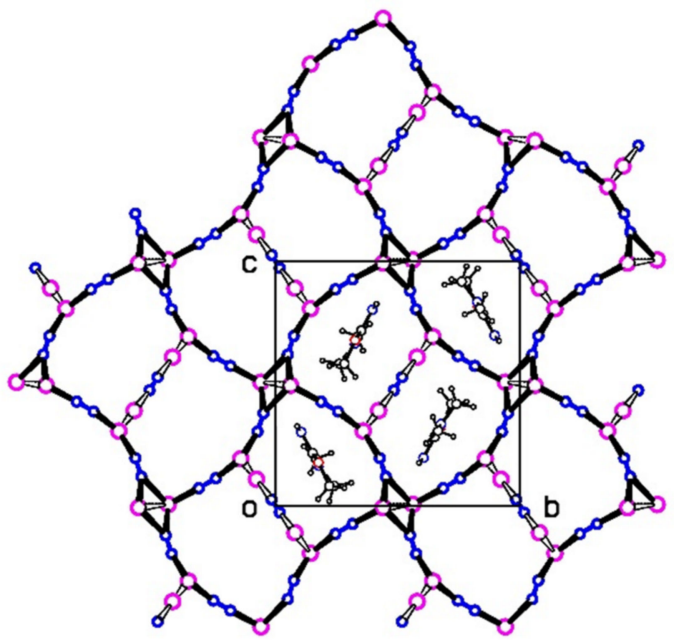

(a)

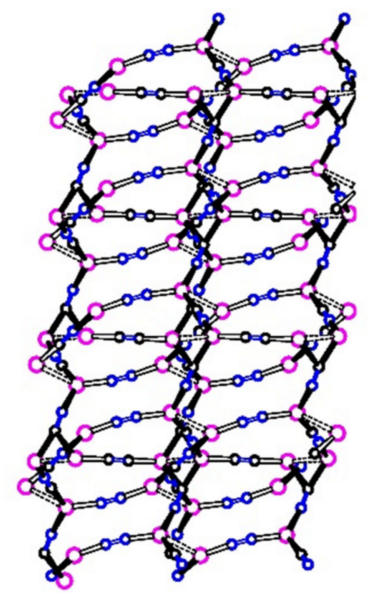

(b)

Figure 4. $\mathrm{CuCN}$ network and packing. (a) View down a-axis, showing the belted 24-membered rings. Oxazolidin cations shown only in the unit cell outline. (b) View down b-axis, showing the rings edge on linked by cyanide groups into the 3D structure. Cell outline is not included in this view. Magenta: $\mathrm{Cu}$; red: O; blue: $\mathrm{N}$; black: $\mathrm{C}$ or $\mathrm{H}$.

\subsection{Spectroscopy and Analyses}

The infrared spectrum of $\mathbf{1}$ (Figure S5) shows strong absorptions due to $\mathrm{C} \equiv \mathrm{N}$ stretching at 2082, 2106, and $2138 \mathrm{~cm}^{-1}$. The absorption at $2106 \mathrm{~cm}^{-1}$ is probably due to $\mu_{2}$ bridging $\mathrm{CN}$ groups 2,3 , and 5 , as we see single absorptions close to this value in our $\mathrm{CuCN}$ structures that contain only this type of $\mathrm{CN}$ group $[13,14]$ and other unpublished results]. The absorption at $2082 \mathrm{~cm}^{-1}$ will be due to the $\mu_{3}$ bridging $\mathrm{CN}$ group as in Reference 1 . The absorption at the higher energy, $2138 \mathrm{~cm}^{-1}$, is likely due to $\mathrm{C} 4 \equiv \mathrm{N} 4$, which bridges two digonal low-coordinate $\mathrm{Cu} 1$ atoms.

Strong absorptions due to the iminium N-H bonds occur at 3357 and $3461 \mathrm{~cm}^{-1}$ which may be compared with the absorptions at 3406 and $3497 \mathrm{~cm}^{-1}$ seen in the guanidinium cation in a CuCN network [14]. There are two other weak bands at 3182 and $3290 \mathrm{~cm}^{-1}$. Other features of the ir spectrum include very strong absorbances at 1303,1519, 1596, and $1705 \mathrm{~cm}^{-1}$.

The elemental analysis of $\mathbf{1}$ gave $24.36 \% \mathrm{C}, 2.12 \% \mathrm{H}$ and $21.16 \% \mathrm{~N}$, which are comparable with the values calculated for the new product, $24.27 \% \mathrm{C}, 2.29 \% \mathrm{H}$ and $21.24 \% \mathrm{~N}$. The $\% \mathrm{Cu}$ of $46.55 \%$ found was somewhat lower than the expected value of $48.16 \%$.

\section{Experimental Section}

Crystal data for $\mathrm{C}_{8} \mathrm{H}_{9} \mathrm{Cu}_{3} \mathrm{~N}_{6} \mathrm{O}(\mathrm{M}=395.84 \mathrm{~g} / \mathrm{mol})$ : crystal was a plate with dimensions $0.36 \times 0.20 \times 0.09 \mathrm{~mm}$, monoclinic, space group P2 $1 / \mathrm{c}$ (no. 14), $\mathrm{a}=6.9393(1) \AA$, $\mathrm{b}=13.4468(3) \AA, \mathrm{c}=13.4972(3) \AA, \beta=95.071(1)^{\circ}, \mathrm{V}=1254.55(4) \AA^{3}, \mathrm{Z}=4, \mathrm{~T}=300(2) \mathrm{K}$, $\mu(\mathrm{MoK} \alpha)=5.03 \mathrm{~mm}^{-1}$, Dcalc $=2.096 \mathrm{~g} / \mathrm{cm}^{3}$, Dmeas $=2.08(1) \mathrm{g} / \mathrm{cm}^{3}, 19,265$ reflections measured $\left(1.0^{\circ} \leq \Theta \leq 27.48^{\circ}, 2867\right.$ unique (Rint $\left.=0.046\right)$, which were used in all calculations. The final $\mathrm{R}_{1}$ was 0.0344 (I $>2 \sigma(\mathrm{I})$ ) and $w \mathrm{R}_{2}$ was 0.0790 (all data) for 175 variables. The structure was solved by the heavy atom method from a Patterson map calculated with SHELXS and refined with SHELXL Version 2017 [15]. All CN groups were modeled with disorder in their orientation. $\mathrm{CN}$ groups 2 and 4 were given $50 \% \mathrm{C} / \mathrm{N}$ occupancies, as they bridged an inversion center, and $\mathrm{CN}$ group 1 because the refined occupancies did not differ 
significantly from $50 \%$. Occupancies for the major orientation for disordered $\mathrm{CN}$ groups 3 and 5 refined to $81(3) \%$ and $78(4) \%$, respectively. Hydrogen atoms on $C$ were constrained at idealized positions, riding on the carbon atoms, with C-H distances of $0.96 \AA$ for methyl groups and $0.97 \AA$ for methylene groups, and isotropic temperature factors $50 \%$ larger than the Ueq of the bonded $\mathrm{C}$ atoms. The iminium $\mathrm{H}$ atoms were refined independently, with only a minimum restraint on distance. The cif file for this structure is included in the Supplementary Materials for this article and has also been deposited with the Cambridge Crystallographic Data Center as CCDC 2088682. These data can be obtained free of charge via http:/ / www.ccdc.cam.ac.uk/ conts/retrieving.html (accessed date: 15 June 2021) or from the CCDC, 12 Union Road, Cambridge CB2 1EZ, UK; Fax: +44 1223 336033; E-mail: deposit@ccdc.cam.ac.uk).

\section{Discussion}

This work has shown the formation of a 3-methyl-1,3-oxazolidin-2-iminium cation via the reaction of a cyanide ion and protonated $\mathrm{N}$-methylethanolamine in aqueous solution in the presence of $\mathrm{CuCN} / \mathrm{NaCN}$. In ongoing work on this system, we are attempting to find reaction conditions and $\mathrm{pH}$ levels that favor the formation of the title compound, to isolate salts of the cation that are independent of the copper cyanide network, and to develop an understanding of the reaction mechanism.

\section{Materials and Methods}

Chemicals were used as obtained from suppliers without further purification. The X-ray structure was determined with diffraction data collected with a Nonius Kappa CCD system (Bruker Axis LLC, Madison, WI, USA) using graphite monochromated MoK $\alpha$ radiation with $\lambda=0.7107 \AA$. Chemical analysis was performed by Robertson Microlit (Ledgewood, NJ, USA). FTIR data were obtained with a Nicolet iS50 FT-IR spectrometer (Thermo Fisher Scientific, Waltham, MA, USA. The SEM image was collected with a Zeiss Evo MA10 Scanning Electron Microscope and the esr spectrum was obtained with a Bruker EMXNano spectrometer.

Supplementary Materials: Figure S1: Checkcif Report, Figure S2: Optical photo of green "crystal" at high magnification; Figure S3: SEM picture of a different green "crystal"; Figure S4: esr spectrum of green sample; Figure S5: Infrared spectrum of title compound. MOL File, cif file.

Author Contributions: P.W.R.C. designed the experiments, carried out the X-ray analysis, analyzed the results and wrote the manuscript. L.N.R. carried out the syntheses and ir spectra. All authors have read and agreed to the published version of the manuscript.

Funding: This research received no external funding.

Institutional Review Board Statement: Not Applicable.

Informed Consent Statement: Not Applicable.

Data Availability Statement: The data presented in this study are available on request from the corresponding author.

Acknowledgments: We gratefully acknowledge support from the chemistry department at Fordham University, and we thank colleagues C. Koenigsmann for assistance with the electron microscopy and C. Bender for the esr measurements. Students A. Felix Varona, T. DaCunha and N. Eisha assisted with follow-up syntheses and density measurements.

Conflicts of Interest: The authors declare no conflict of interest.

\section{References}

1. Koenigsmann, C.; Rachid, L.N.; Sheedy, C.M.; Corfield, P.W.R. Synthesis, decomposition studies and crystal structure of a three-dimensional CuCN network structure with protonated N-methylethanolamine as the guest cation. Acta Crystallogr. Sect. C Struct. Chem. 2020, 76, 405-411. [CrossRef] [PubMed]

2. Wiley, R.H. The chemistry of the oxazoles. Chem. Rev. 1945, 37, 389-437. [CrossRef] [PubMed] 
3. Lakhan, R.; Ternai, B. Advances in oxazole chemistry. Adv. Heterocycl. Chem. 1974, 17, 99-211.

4. Turchi, I.J.; Dewar, M.J.S. The Chemistry of Oxazoles. Chem. Rev. 1975, 75, 401-442. [CrossRef]

5. Turchi, I.J. Oxazole chemistry: A review of recent advances. Ind. Eng. Chem. Prod. Res. Dev. 1981, 20, 32-76. [CrossRef]

6. Kakkar, S.; Narasimhan, B. A comprehensive review on biological activities of oxazole derivatives. BMC Chem. 2019, 13, 16. [CrossRef] [PubMed]

7. Groom, C.R.; Bruno, I.J.; Lightfoot, M.P.; Ward, S.C. The Cambridge Structural Database. Acta Cryst. B 2016, 72, 317-325. [CrossRef] [PubMed]

8. Rynearson, K.D.; Dutta, S.; Tran, K.; Dibrov, S.M.; Hermann, T. Synthesis of Oxazole Analogs of Streptolidine Lactam. Eur. J. Org. Chem. 2013, 2013, 7337-7342. [CrossRef]

9. Cruz, A.; Padilla-Martínez, I.I.; García-Báez, E.V.; Contreras, R. Reactivity of Chlorodeoxypseudoephedrines with Oxo-, Thio-, and Selenocyanates. Tetrahedron Asymmetry 2007, 18, 123-130. [CrossRef]

10. Misaiszek, C.; Jarry, C.; Ouhabi, J.; Carpy, Y. Synthesis and Structural Study of 3-(2-propanone) 5-phenoxymethyl 2iminooxazolidine: C13H16N2O3HCl. Comptes Rendue L'Academie Sci. Ser. II 1988, 307, 1189-1193.

11. Satyachand Harisomayajula, N.V.; Makovetskyi, S.; Tsai, Y.-C. Cuprophilic Interactions in and between Molecular Entities. Chem. Eur. J. 2019, 25, 8936-8954. [CrossRef] [PubMed]

12. Stocker, F.B.; Staeva, T.P.; Rienstra, C.M.; Britton, D. Crystal Structures of a Series of Complexes Produced by Reactions of Copper(I) Cyanide with Diamines. Inorg. Chem. 1999, 38, 984-991. [CrossRef]

13. Corfield, P.W.R.; Stavola, T.J. Poly[diethylammonium [tetra- $\mu_{2}$-cyanido- $\kappa^{8} C: N$-tricuprate(I)]], a two-dimensional network solid. IUCrData 2020, 5, x200968. [CrossRef]

14. Corfield, P.W.R.; Dayrit, J.R. Poly[1,3-Dimethyltetrahydropyrimidin-2(1H)-iminium [tri- $\mu_{2}$-cyanido- $\left.\left.{ }^{6} \mathrm{C}: \mathrm{N}-\mathrm{dicuprate}(\mathrm{I})\right]\right]$. Molbank 2020, 4, M1170. [CrossRef]

15. Sheldrick, G.M. Crystal structure refinement with SHELXL. Acta Crystallogr. Sect. C Struct. Chem. 2015, 71, 3-8. [CrossRef] 